\title{
Does new product growth accelerate across technology generations?
}

\author{
Stefan Stremersch • Eitan Muller • Renana Peres
}

(C) The Author(s) 2009. This article is published with open access at Springerlink.com

\begin{abstract}
The academic literature on the growth acceleration of new products presents a paradox. On the one hand, the diffusion literature concludes that more recently introduced products show faster diffusion than older ones. On the other hand, technology generation literature argues that growth rate, at least as measured by diffusion parameters, remains constant across generations. We resolve this apparent paradox by testing whether growth acceleration occurs across technology generations while controlling for the passing of time. We check acceleration across 39 distinct technology generations in 12 product markets. The results show that intergeneration acceleration occurs in time to takeoff but not with respect to
\end{abstract}

\section{S. Stremersch}

Erasmus School of Economics, Erasmus University, Rotterdam, The Netherlands

e-mail: stremersch@ese.eur.nl

\section{S. Stremersch}

IESE Business School, Barcelona, Spain

E. Muller

Stern School of Business, New York University, New York, NY, USA

e-mail: emuller@stern.nyu.edu

E. Muller

Recanati Graduate School of Business, Tel Aviv University, Tel Aviv, Israel

R. Peres

School of Business Administration, Hebrew University of Jerusalem, Jerusalem, Israel

R. Peres $(\bowtie)$

The Wharton School, University of Pennsylvania, Philadelphia, PA, USA

e-mail: peresren@wharton.upenn.edu 
diffusion parameters (i.e., $p$ and $q$ ). We show that takeoff acceleration is mostly driven by technology vintage (i.e., the passage of time) rather than generational shifts. Thus, time is a factor that accelerates early growth, but generational shifts do not. This result also holds when controlling for the effects of market vintage when the market is either business-to-business or business-to-consumer as well as when the technology is process- or product-based.

Keywords Diffusion A Acceleration · Technology generations · Takeoff

\section{Introduction}

Despite obvious interest among practitioners, as well as marketing academics, in the acceleration of diffusion processes across generations and over time, the academic literature on this subject presents a curious paradox. On the one hand, the diffusion acceleration literature compares the rate of growth across product markets over time. By and large, these studies conclude that more recent product markets show faster diffusion than older ones (Agarwal and Bayus 2002; Chandrasekaran and Tellis 2008; Kohli et al. 1999 ${ }^{1}$; Van den Bulte 2000 and 2002; Van den Bulte and Stremersch 2004 and 2008). Exceptions to this generalized finding are rare (Bayus 1994) and contested on the grounds of estimation bias and invalid inference (Van den Bulte 2004). On the other hand, the technology generation literature either treats diffusion parameters as constant across generations or else shows that the difference in the explanatory power (if one assumes they do change) is minimal or nonexistent. Thus, the constancy of growth across generations is a key element of several studies across multiple product categories (Bass and Bass 2001, 2004; Kim et al. 2000; Mahajan and Muller 1996; Norton and Bass 1987, 1992). Exceptions to these consistent findings are not only rare (Pae and Lehmann 2003; Danaher et al. 2001) but also contested (Van den Bulte 2004).

This paper attempts to resolve this paradox by testing whether growth acceleration occurs across technology generations while controlling for the passage of time. We analyze acceleration across 39 distinct technology generations in 12 product markets. The results show that intergeneration acceleration occurs in the time to takeoff but not in the diffusion parameters. That is, newer generations of a product enjoy a shorter left tail but a similar overall growth process.

More importantly, this paradox is resolved by examining whether this acceleration in the time to takeoff is mostly driven by technology vintage (i.e., the passage of time) or by technology generation. We show that the acceleration in the time to takeoff is due to the passage of time rather than to generational shifts. Thus, time is indeed a factor that accelerates early growth while generational shifts do not.

\footnotetext{
${ }^{1}$ Measuring acceleration is possible by following Kohli et al. (1999) and by regressing the Bass coefficients against the time of introduction. Based on this approach, one can see that the internal coefficient $q$ significantly increases over time.
} 


\section{Terminology}

We use the following terms that require careful, upfront definitions.

Technology generation A technology generation is a set of product brands and models similar in customer-perceived functionality characteristics (Bass and Bass 2001). To understand this concept better, we refer to the market definition framework of Abell (1980), which includes three dimensions, namely, technology, customer, and function. On the technology dimension, a new technology generation may be characterized in comparison to a previous generation not only by the use of a novel technology (e.g., digital television versus electronic color television) but also by the novel application of an existing technology (e.g., electronic color television versus electronic black and white television) or the novel performance level of an existing technology (e.g., successive PC generations). The new generation typically offers a significant improvement in performance or benefits over the previous generation. On the customer dimension, a new technology generation may be used by existing customers (i.e., cannibalization or migration), but it may also significantly expand the market to new customers (Islam and Meade 1997). On the function dimension, a new technology generation should perform a function similar to the old technology (e.g., DVD versus VCR). If this is not the case, it is not a new technology generation in an existing market but rather the birth of a new market (e.g., radio versus TV). If we consider video game consoles as an example, then, on the basis of this definition of technology generation, we can say that 16-bit video game consoles are fourth-generation consoles. The first-generation consoles were characterized by the game code being "hardcoded" in the microchip of the device in such a way that no games could be added. These consoles included Magnavox Odyssey, Atari (Pong), Coleco Telstar, and Nintendo Color TV Game, all of which were launched between 1972 and 1977. The second-generation consoles (1977-1984) included a general-purpose processor while game cartridges contained programs burnt on ROM chips. The best-known platform of the second generation is the Atari 2600. The third-generation consoles (also known as the 8-bit generation) originated with Nintendo's Famicom (1985).

Technology vintage Technology vintage is the year in which the first model of a new technology is introduced commercially. Note that some researchers refer to vintage as the year at which an innovation reaches 5\% market penetration rather than the launch year (Van den Bulte 2000). The disadvantage of this latter approach for the study of early growth is that it ignores the considerable differences between the growth rates of different products at these early stages. While some reach 5\% rather fast (e.g., cellular phones), others have long left tails (e.g., fax machines). Our definition implies that the vintage of the 16-bit generation video game consoles is 1989 (Sega Genesis introduction).

Takeoff After introduction, the sales evolution of any generation undergoes a typical pattern, which is marked by an introduction period in which sales linger at low levels. At a certain point in time, it breaks into rapid growth often marked by extremely high growth rates as high as $300-400 \%$. We call this point the takeoff, 
following Golder and Tellis (1997), Stremersch et al. (2007), Tellis et al. (2003), and Van Everdingen et al. (2009). The takeoff is often regarded as the point at which the life cycle of a new product makes a transition from the introduction stage to the growth stage (Golder and Tellis 1997, 2004). For example, the takeoff of 16-bit generation video game consoles occurred in 1990. The precise measurement of takeoff is specified below.

\section{Data}

Our dataset includes generational sales data on a large number of product markets. The types of product markets we sample are quite typical for research on multigeneration diffusion (Bass and Bass 2004, 2001; Pae and Lehmann 2003). Our data sources included Bass (2004), Christensen (1993), Consumer Electronics Association (CEA), the Digital Entertainment Group, Disktrend Inc., Kovac (1969), the NPD group, Phister (1979), and the US Statistical Abstract. Also, fellow academics, such as Frank Bass, Portia Bass, Donald Lehmann, and Jae Pae graciously contributed to our sample by providing us with data. As one can see from Table 1, we have data on 39 generations in 12 product markets. We identified the technology generation and technology vintage using the historical method (Golder 2000) with frequent reference cross-checking. Interestingly, with respect to intergeneration time, we do not find any evidence that intergeneration launch times are decreasing, which is a widely held belief among researchers and practitioners (Kuester et al. 1998; Sood and Tellis 2005). In our dataset, we find that the intergeneration times actually increase in five product markets, namely, television, video game console, personal computer, rigid disk drive, and steel making. For two product markets (i.e., the IBM GP computer and tire cord), there is no clear and consistent pattern. For the other five product markets (that is, audio system, flexible disk drive, home entertainment, oil cracking, optical disk drive), we are unable to make definitive conclusions as we only have data on two generations.

\section{The time to takeoff across technology generations}

We identify the time at which takeoff occurs for each technology generation in each market with the heuristic developed by Tellis et al. (2003) and study whether acceleration occurs in the time to takeoff across technology generations. This heuristic specifies, for each penetration level, the growth threshold required to generate a takeoff. The values of the threshold function are available from the authors upon request. The threshold function varies from $600 \%$ at $0.1 \%$ market penetration to $25 \%$ at $3.5 \%$ market penetration. The last two columns of Table 1 report the takeoff year and the time to takeoff. They demonstrate an acceleration in the time to takeoff in nine out of 12 product markets (i.e., audio system, flexible disk drive, home entertainment, oil cracking, optical disk drive, steel making, television, tire cord, and video game console) while we find a constant time to takeoff in two product markets (namely, IBM GP computer and personal computer) and an 
Table 1 Thirty-nine generations in 12 product markets

\begin{tabular}{|c|c|c|c|c|c|c|c|}
\hline Market & $\begin{array}{l}\text { Geographic } \\
\text { scope }\end{array}$ & Generation & $\begin{array}{l}\text { Years in } \\
\text { sample }\end{array}$ & $\begin{array}{l}\text { Technology } \\
\text { vintage }\end{array}$ & $\begin{array}{l}\text { Intergeneration } \\
\text { time }\end{array}$ & $\begin{array}{l}\text { Takeoff } \\
\text { year }\end{array}$ & $\begin{array}{l}\text { Time } \\
\text { to } \\
\text { takeoff }\end{array}$ \\
\hline \multirow{2}{*}{$\begin{array}{l}\text { Audio } \\
\text { system }\end{array}$} & USA & Tape deck & $1956-2004$ & 1953 & N/A & 1961 & 8 \\
\hline & USA & CD player & 1983-2004 & 1983 & 30 & 1984 & 1 \\
\hline \multirow{2}{*}{$\begin{array}{l}\text { Flexible disk } \\
\text { drive }\end{array}$} & World & $5.25^{\prime \prime}$ & 1976-1998 & 1976 & N/A & 1981 & 5 \\
\hline & World & $3.5^{\prime \prime}$ & 1981-1998 & 1981 & 5 & 1984 & 3 \\
\hline \multirow{2}{*}{$\begin{array}{l}\text { Home } \\
\text { entertainment }\end{array}$} & USA & VCR & 1974-2004 & 1972 & N/A & 1977 & 5 \\
\hline & USA & DVD & $1997-2004$ & 1997 & 25 & 1998 & 1 \\
\hline \multirow[t]{4}{*}{$\begin{array}{l}\text { IBM GP } \\
\text { computer }\end{array}$} & USA & $\begin{array}{l}701,650,702 \\
704,705,709\end{array}$ & $1955-1975$ & 1955 & N/A & 1956 & 1 \\
\hline & USA & $\begin{array}{l}1620,1401,1410 \\
1440,1460 \\
7090,7070 \\
7074,704 x \\
7010\end{array}$ & $1959-1978$ & 1959 & 4 & 1960 & 1 \\
\hline & USA & $360,1130,1800$ & $1965-1978$ & 1965 & 6 & 1966 & 1 \\
\hline & USA & $\begin{array}{l}370, \text { system } 3, \\
\text { system } 7\end{array}$ & $1970-1978$ & 1970 & 5 & 1972 & 1 \\
\hline \multirow[t]{2}{*}{ Oil cracking } & USA & Catalytic cracking & 1941-1992 & 1938 & N/A & 1945 & 7 \\
\hline & USA & Hydrocracking & 1963-1994 & 1962 & 24 & 1966 & 4 \\
\hline \multirow{2}{*}{$\begin{array}{l}\text { Optical disk } \\
\text { drive }\end{array}$} & World & CD-ROM & 1985-2002 & 1985 & N/A & 1990 & 5 \\
\hline & World & DVD-ROM & 1996-2002 & 1996 & 11 & 1997 & 1 \\
\hline \multirow[t]{9}{*}{$\begin{array}{l}\text { Personal } \\
\text { computer }\end{array}$} & USA & $\begin{array}{l}\text { Desktop } \\
\text { PC kits }\end{array}$ & 1975-1979 & 1975 & N/A & 1976 & 1 \\
\hline & USA & $\begin{array}{l}\text { Manufactured } \\
\text { PC }\end{array}$ & $1977-1982$ & 1977 & 2 & 1978 & 1 \\
\hline & USA & $\begin{array}{l}\text { Application } \\
\text { software home } \\
\text { computer }\end{array}$ & 1979-1985 & 1979 & 2 & 1980 & 1 \\
\hline & USA & $\begin{array}{l}\text { IBM PC } \\
\text { compatible }\end{array}$ & $1982-1988$ & 1982 & 3 & 1983 & 1 \\
\hline & USA & $\begin{array}{l}\text { Hard drive home } \\
\text { computer }\end{array}$ & 1984-1991 & 1984 & 2 & 1985 & 1 \\
\hline & USA & 32-bit desktop & 1987-1994 & 1987 & 3 & 1988 & 1 \\
\hline & USA & Windows PC & 1990-1997 & 1990 & 3 & 1991 & 1 \\
\hline & USA & Multimedia PC & $1994-2000$ & 1993 & 3 & 1994 & 1 \\
\hline & USA & Internet PC & $1997-2000$ & 1997 & 3 & 1998 & 1 \\
\hline \multirow[t]{3}{*}{ Rigid disk drive } & World & $5.25^{\prime \prime}$ & 1980-1998 & 1980 & N/A & 1982 & 2 \\
\hline & World & $3.5^{\prime \prime}$ & 1983-1998 & 1983 & 3 & 1987 & 4 \\
\hline & World & $2.5^{\prime \prime}$ & 1988-1998 & 1988 & 5 & 1990 & 2 \\
\hline \multirow[t]{3}{*}{ Steel making } & USA & Open hearth & 1869-1991 & 1868 & N/A & 1905 & 37 \\
\hline & USA & Electric furnace & 1909-1999 & 1905 & 37 & 1941 & 36 \\
\hline & USA & Basic oxygen & 1955-1999 & 1954 & 49 & 1963 & 9 \\
\hline \multirow[t]{3}{*}{ Television } & USA & $\begin{array}{l}\text { Electronic } \\
\text { black and white }\end{array}$ & 1946-2004 & 1939 & N/A & 1947 & 8 \\
\hline & USA & Electronic color & 1954-2004 & 1954 & 15 & 1962 & 8 \\
\hline & USA & Digital & $1998-2004$ & 1998 & 44 & 1999 & 1 \\
\hline
\end{tabular}


Table 1 (continued)

\begin{tabular}{|c|c|c|c|c|c|c|c|}
\hline Market & $\begin{array}{l}\text { Geographic } \\
\text { scope }\end{array}$ & Generation & $\begin{array}{l}\text { Years in } \\
\text { sample }\end{array}$ & $\begin{array}{l}\text { Technology } \\
\text { vintage }\end{array}$ & $\begin{array}{l}\text { Intergeneration } \\
\text { time }\end{array}$ & $\begin{array}{l}\text { Takeoff } \\
\text { year }\end{array}$ & $\begin{array}{l}\text { Time } \\
\text { to } \\
\text { takeoff }\end{array}$ \\
\hline \multirow[t]{4}{*}{ Tire cord } & USA & Cotton & 1910-1955 & 1910 & N/A & 1918 & 8 \\
\hline & USA & Rayon & 1938-1979 & 1938 & 28 & 1944 & 6 \\
\hline & USA & Nylon & 1947-1979 & 1947 & 9 & 1953 & 6 \\
\hline & USA & Polyester & $1962-1979$ & 1962 & 15 & 1966 & 4 \\
\hline \multirow[t]{3}{*}{$\begin{array}{l}\text { Video game } \\
\text { console }\end{array}$} & USA & $\begin{array}{l}\text { 16-bit } \\
\text { machines }\end{array}$ & 1989-2004 & 1989 & N/A & 1990 & 1 \\
\hline & USA & $\begin{array}{l}\text { 32-64-bit } \\
\text { machines }\end{array}$ & 1993-2004 & 1993 & 4 & 1994 & 1 \\
\hline & USA & $\begin{array}{l}\text { 128-bit } \\
\text { machines }\end{array}$ & 1999-2004 & 1999 & 6 & 1999 & 0 \\
\hline
\end{tabular}

No. of markets with accelerating time to takeoff, $9 / 12$; no. of markets with constant time to takeoff, $2 / 12$; and no. of markets with inconsistent time to takeoff across generations, 1/12

inconsistent pattern in the case of rigid disk drive. This finding provides support for acceleration in the time to takeoff across technology generations.

To further support the results, we generate additional metrics in Table 2, which reports three statistics. We report these statistics for all generations in our data from generation 1 (G1) to generation 9 (G9) even though statistics on generations 4 to 9 are relatively less reliable due to the small number of product markets with more than three generations. The first statistic in Table 2 is the average time to takeoff for a generation, which is the average across all markets of the generation's time to takeoff. We find that this average declines from 7.33 for generation G1 to 5.58 for G2 and then to 2.86 for G3.

As markets may strongly diverge in the average time to takeoff, we also correct for the product market by developing a second statistic, namely, the average lag or lead time to takeoff (Tellis et al. 2003). This statistic is calculated by first averaging the time to takeoff across all generations for each market and

Table 2 Summary statistics on the time to takeoff

\begin{tabular}{|c|c|c|c|c|c|}
\hline & G1 & G2 & G3 & G4 & G5-G9 \\
\hline $\begin{array}{l}\text { Average time to } \\
\text { takeoff (years) }\end{array}$ & 7.33 & 5.58 & 2.86 & 2.00 & 1.00 \\
\hline $\begin{array}{l}\text { Average lag } \\
(+) / \text { lead( }(-) \\
\text { in time to takeoff }\end{array}$ & 1.97 & 0.22 & -3.48 & -0.67 & 0.00 \\
\hline $\begin{array}{l}\text { Average } \% \\
\text { reduction in time } \\
\text { to takeoff }(\%)\end{array}$ & N/A & $-22.13 \%$ & $-30.36 \%$ & $-11.11 \%$ & $0.00 \%$ \\
\hline Number of markets & 12 & 12 & 7 & 3 & 2 \\
\hline
\end{tabular}


then subtracting this average from the time to takeoff of each generation for each market. The average of these lags and leads across all markets is the second statistic in Table 2. The results for this second statistic imply that, on average, the time to takeoff of the first generation lags behind the average generation in a given market by almost 2 years. The time to takeoff of the second generation is very close to the time to takeoff of the average generation while the time to takeoff of the third generation leads the time to takeoff of the average generation by more than 3 years. A third statistic is the average reduction in the time to takeoff in percentage terms across generations. This statistic is calculated by first taking the percentage change in the time to takeoff from one generation to the next for each product market and for each generation. These percentage changes are then averaged across all markets per generation. We see that the time to takeoff declines consistently across generations 2,3 , and 4 .

We also measured the evolution in the time to takeoff across three time periods for products that were introduced before 1940 (i.e., before World War II), between 1940 and 1980, and after 1980. We find acceleration in the time to takeoff changes from 17 years before 1940 to 3.73 years between 1940 and 1980 and then, finally moves toward 1.55 years after 1980; note that these findings are in line with those of Chandrasekaran and Tellis (2008).

\section{Theoretical perspectives on the effects of vintage and generation on acceleration in the time to takeoff}

The reasons for acceleration in the time to takeoff over technology generations may lie in the succession of generations (i.e., the technology generation) or the passing of time (that is, the technology vintage).

\subsection{Technology generation}

We discuss two main sources related to generational shifts that can contribute to takeoff acceleration. The first factor is the presence of standard battles. The second factor is the effort required from consumers to adopt and use a new product and the extent to which the product requires a change in their usage behaviors and habits.

Standards battles The first generation in a product market is often plagued by standard battles that subsequent generations may not face. Examples in our data include the standard battles fought in the first-generation markets for tape deck and VCR. In contrast, the second product generation in these markets (namely, CD and DVD player, respectively) did not face such battles as Sony and Philips agreed on a common standard before CD's and DVD's commercial launch. Since the presence of standards battles slows down early growth (Goldenberg et al. 2010; Van den Bulte and Stremersch 2004), one may expect the time to takeoff to be relatively long in the first generation of products (e.g., 8 years for the tape deck and 5 years for the VCR) but comparably shorter in the second generation (e.g., only 1 year in the cases of both CD and DVD player). 
Adoption efforts of consumers Earlier generations of products may require a more dramatic change in behavior from consumers as these products may be more novel. VCRs opened up new experiences, such as recording, time-shifting, and the viewing of rental movies while DVD players did not. Kohli et al. (1999) have shown that products that require a dramatic change in behavior have longer incubation periods. Their conceptualization of incubation time as the period between the time at which a product is ready for launch and the time of substantial sales is akin to the concept of the time to takeoff.

\subsection{Technology vintage}

We discuss two potential contributions to takeoff acceleration across generation vintage, namely, increasing affordability and better communication and information channels.

Increasing affordability Golder and Tellis (1997) show that, at some time near takeoff, new products cross a price level that makes them more affordable. Such price declines may be caused by learning effects on the supplier side. This may be especially the case for the products we study here, which Parker (1992) would refer to as "necessity" products because their markets are long lived and show high ultimate penetration levels. Parker also showed that in such necessity markets, early market growth will be sensitive to price declines. One should note that the price of the previous generation might also decline around the time of introduction of a new generation, and this might have an effect on the diffusion of the latter as well.

The learning rates of suppliers may also increase over time. The longer their experience in the market is the greater is the extent of learning they have undergone. For instance, the DVD player was introduced in 1997 at an average price of $\$ 500$; this price dropped to $\$ 250$ by 1999 . The dominant manufacturers Sony, Philips, and Panasonic were all manufacturers with a substantial history of experience in the VCR market. In contrast, the VCR was initially priced at approximately $\$ 600$ in 1972 , increased in price by 1975 to $\$ 675$, and by 1976 , to $\$ 714$ before dropping to $\$ 564$ in 1977, which was the year the VCR took off (nominal prices; source: the CEA). The VCR was also a very new application for the companies that manufactured it. In sum, the DVD player decreased in price much faster than the VCR did probably because of faster learning among manufacturers. In addition, consumer purchasing power has also grown considerably over time (Van den Bulte 2000), which may make more recent technology generations affordable to more consumers than older technology generations.

Better communication and information channels Communication and information channels have improved over time. The extensive use of these channels may be required to educate and inform potential customers about the benefits of a new technology (Agarwal and Bayus 2002). More informed consumers may adopt an innovation faster than consumers who are less informed. Therefore, improvements in communication and information channels may shorten the time to takeoff with respect to generation and vintage. 


\section{Empirical evidence on the effects of vintage and generation on acceleration in the time to takeoff}

We now show that, although there is theoretical support for the impact of both generation and vintage, empirical analysis indicates that only vintage has a significant influence on the time to takeoff. Given that our model does not contain time-varying covariates and is estimated using sparse data, we opt for a simple model structure and a parsimonious set of predictors. The model structure is Cox's proportional hazard model (Cox 1972, 1975), but it is estimated using the semiparametric estimator developed by Han and Hausman (1990). This estimator has two main advantages. First, our estimator is a discrete time specification while Cox's original estimator is a continuous time estimator. Second, Cox's estimator is problematic in the case of many ties. Since our data are discrete and contain many ties, we opted to employ an alternate estimator.

We include six independent variables in our model: (1) technology vintage, TECHVIN; (2) technology generation, TECHGEN; (3) market vintage, MARVIN1 (i.e., product markets originating pre-WWI) and MARVIN2 (i.e., product markets originating between WWI and WWII); (4) two dummies, namely, B2B and PROC, to control for the type of technology market with respect to whether the market is a business-to-business market $(\mathrm{B} 2 \mathrm{~B}=1)$ or business-to-consumer market $(\mathrm{B} 2 \mathrm{~B}=0)$ and whether it is a process market $(\mathrm{PROC}=1)$ or a product market $(\mathrm{PROC}=0)$. The correlation matrix of these six covariates can be found in Table 3.

To evaluate robustness, we specify multiple models; see Table 4. The first three models regress the hazard of takeoff separately on technology vintage (TECHVIN) in model 1, technology generation (TECHGEN) in model 2, and the control variables for market vintage (MARVIN1 and MARVIN2) and the type of technology market (B2B and PROCESS) in model 3. Model 4 regresses hazard of takeoff on technology vintage and technology generation while model 5 specifies the full model.

The full model (model 5) shows consistently that the higher is the technology vintage $\left(\beta_{\text {TECHVIN }}=-0.09, p<0.01\right)$ the shorter is the time to takeoff. The higher is the technology generation, the shorter is the time to takeoff; however, this effect is

Table 3 Correlation matrix of independent variables

\begin{tabular}{lcccccc}
\hline & $\begin{array}{l}\text { Time to } \\
\text { takeoff }\end{array}$ & $\begin{array}{l}\text { Technology } \\
\text { vintage }\end{array}$ & $\begin{array}{l}\text { Technology } \\
\text { generation }\end{array}$ & $\begin{array}{l}\text { Pre-WWI } \\
\text { market }\end{array}$ & $\begin{array}{l}\text { Between WWI } \\
\text { and WWII }\end{array}$ & $\begin{array}{l}\text { B2B } \\
\text { technology }\end{array}$ \\
\hline $\begin{array}{c}\text { Technology } \\
\text { vintage }\end{array}$ & -0.83 & & & & \\
$\begin{array}{c}\text { Technology } \\
\text { generation }\end{array}$ & -0.40 & 0.39 & & & \\
$\begin{array}{l}\text { Pre-WWI market } \\
\text { Between WWI }\end{array}$ & 0.64 & -0.70 & -0.09 & & \\
and WWII & 0.27 & -0.14 & -0.17 & -0.18 & \\
$\begin{array}{l}\text { B2B technology } \\
\text { Process }\end{array}$ & 0.36 & -0.44 & -0.32 & 0.46 & -0.09 \\
technology & 0.67 & -0.72 & -0.16 & 0.85 & 0.15 \\
\hline
\end{tabular}




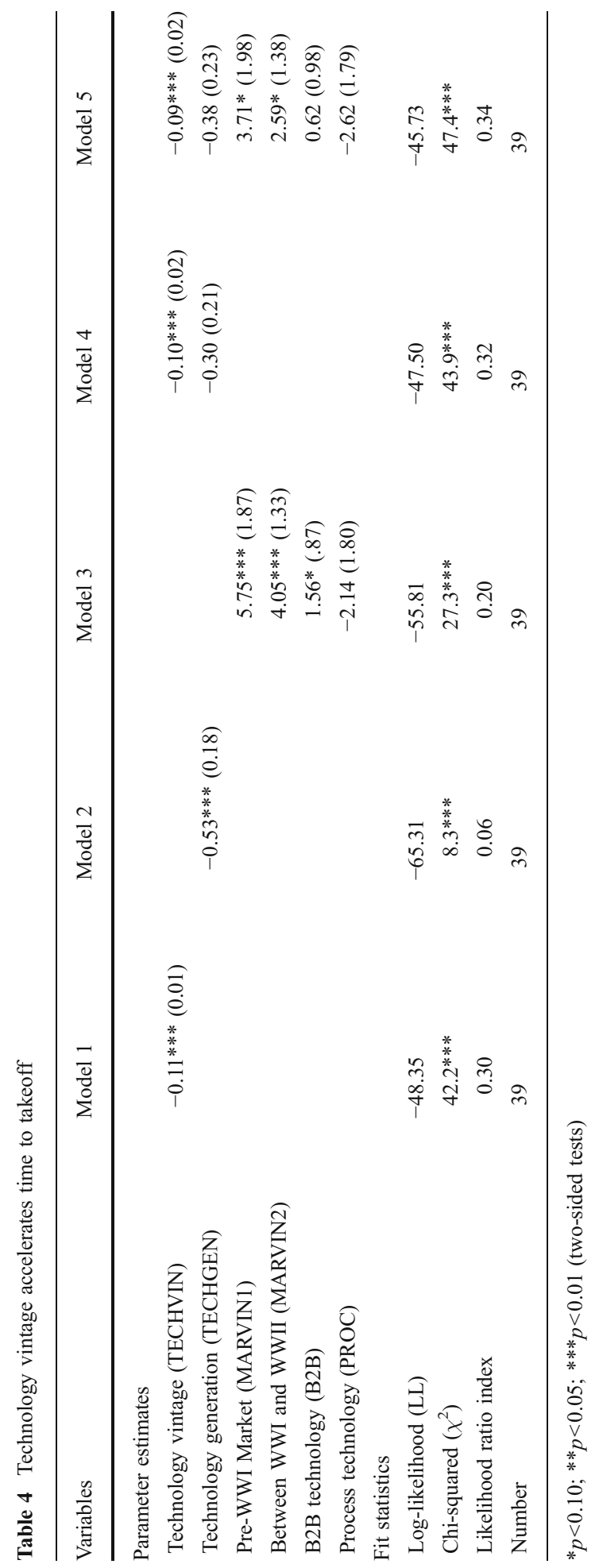


not statistically significant $\left(\beta_{T E C H G E N}=-0.38 ; p>0.10\right)$. The only model in which technology generation has a statistically significant effect on the time to takeoff is model $2\left(\beta_{T E C H G E N}=-0.53 ; p<0.01\right)$ in which technology generation is included as the sole predictor. Results of models 4 and 5 show, however, that the variance captured by technology generation in model 2 is in part due to the passing of time (i.e., technology vintage) rather than generational shifts.

The effects of market vintage are marginally significant when included in model 5 $\left(\beta_{\text {MARVINI }}=3.71 ; p<0.10 ; \beta_{\text {MARVIN } 2}=2.59 ; p<0.10\right)$ while they are strongly significant in model $3\left(\beta_{\text {MARVINI }}=5.75 ; p<0.01 ; \beta_{\text {MARVIN } 2}=4.05 ; p<0.01\right)$. Thus, technology generations in markets that originated before WWI take longer to take off than technology generations in markets that originated after WWII. Technology generations in markets that originated between WWI and WWII, to a lesser extent, also take longer to take off than technology generations in markets that originated after WWII. The effects of variables B2B (i.e., whether a product is business-to-business or business-to-consumer) and PROC (that is, whether it concerns a process or a tangible product) are not significant at the 0.10 level in model 5 while, when regressed without TECHVIN and TECHGEN, B2B products have a marginally longer time to takeoff.

We evaluate the fit of the model in several ways. From comparing the maximized value of the log-likelihood function, we learn that it is mostly technology vintage that explains the variation in the time to takeoff rather than any other variable in the model. The $\chi^{2}$-statistic is significant in all models. We also present the likelihood ratio index (LRI). The LRI is high at 0.34 for model 5 as compared with prior studies that have attempted to explain takeoff. Golder and Tellis (1997) reported an LRI of 0.31 (though they referred to it as $\mathrm{U}^{2}$ ) while Tellis et al. (2003) reported an LRI of 0.18 for the full model.

To test the sensitivity of our results, we also tested alternative models. We implemented a model in which we first took the natural logarithm of technology generation and technology vintage; this model shows a fit that is very similar to that of model 5 presented above. Moreover, the effects we find are very similar as well. We can also think of alternative ways of specifying the technology generation variable. For instance, one could expect the technology generations after generation 3 to be noninformative or even sensitive to biases given that they are based on very few markets. Therefore, an alternative operationalization would be a generation variable in three categories, namely generation $1(=1)$, generation $2(=2)$, and generation 3 or higher $(=3)$. This alternative coding produced very similar results. The only difference was that the PROC dummy turned marginally significant in the full model. One may also be concerned about the categorical nature of our technology generation variable. An alternative would be a dummy coding. Thus, we could include two dummies in Eqs. 1 and 2, that is, one for generation 2 and one for generation 3 and higher, thus using generation 1 as the base. Such an analysis also produces findings similar to those presented in Table 4 . The only difference is that the PROC dummy becomes marginally significant in the full model. To check to what extent our estimation is affected by sample composition, we also deleted one product market at a time and re-estimated all models. There were no sign reversals on any of the coefficients and very few changes in the significance level.

We also checked for interaction effects of MARVIN with TECHVIN. We estimated a separate TECHVIN effect for each of the MARVIN periods, that is, before WWI, 
between WWI and WWII, and after WWII. The results are that the TECHVIN effect is of equal size in all these periods at $-0.090,-0.091$, and -0.092 , respectively.

Another robustness test is to assess the degree to which our results are sensitive to the measurement method for takeoff. To do so, we used an alternative method suggested by Agarwal and Bayus (2002). This method uses discriminant analysis to identify time intervals as pre- or post-takeoff based on the mean growth rate. We were able to identify takeoff with this method for all but four technology generations (G4 of IBM GP computer, G9 of PC, and G1 and G3 of steel making). The reason for not being able to identify takeoff in these four cases is that this alternative method works well on long and smooth sales patterns, but it becomes less robust in the case of short or unstable sales patterns. Using this alternate method, we arrive at very similar conclusions as those found based on our own method. Out of the 35 generations for which takeoff could be measured by both methods, 31 show takeoff to occur in the same year as established by the heuristic of Tellis et al. (2003). For the remaining four (G1 of audio systems, G1 of oil cracking, G2 of optical disk drives, and G2 of rigid disk drives), the difference in takeoff is 1 year $(1962,1946$, 1998, and 1986, respectively). Therefore, our findings regarding takeoff acceleration and the drivers of takeoff acceleration remain the same.

\section{Diffusion parameters across technology generations}

Takeoff is an early growth metric, and thus, one can question whether acceleration also occurs in diffusion parameters. We use a technological substitution model to estimate the acceleration in diffusion parameters. Related models are those developed by Norton and Bass (1987) and Mahajan and Muller (1996). Unfortunately, these models are not suitable for our data since they assume that after the entry of the second generation, the first generation either entirely stops (Norton and Bass 1987) or is considerably constrained (Mahajan and Muller 1996) in terms of the acquisition of new customers, which is a situation that does not match our results. When applied to our data, these models either failed to converge or yielded poor fits. Thus, we constructed a new model much along the lines of Mahajan and Muller (1996) but with a more precise specification of the substitution process. The model is described in the Appendix.

In order to check for acceleration, two methods are possible. The first is to estimate a set of equations with different parameters $p_{i}$ and $q_{i}$ for each generation $i$, and the second is to assume a uniform acceleration rate, that is, to define an acceleration rate $\delta$ that is identical for $q$ and $p$, and does not change over generations. Thus, $p_{i}=(1+\delta) p_{i-1}$ and $q_{i}=(1+\delta) q_{i-1}$ for each generation $i$. We report the results of the latter method as using uniform acceleration significantly reduces the number of parameters and enables an explicit, straightforward acceleration analysis. This is especially relevant for products with many generations.

For each product, we applied the appropriate version of the equation set from the Appendix according to the number of generations and then estimated the parameters. One should note that some of the data are sales data that obscure the substitution process of the upgraders since upgraders may repeat-purchase each generation and thus be re-counted in each generation's sales figures. In order to retrieve the adoption 
data from the sales data, we used the method developed by Tellis et al. (2003). The $p$ and $q$ estimates have face validity and remain within the typical range previously reported for diffusion parameters. Namely, the average $p$ is 0.024 while the average $q$ is 0.3 . The estimates for the market potential seem also coherent with market reality and industry expectations. The adjusted R-squared measures are reasonable except in three cases in which the generational data covered a short time window, namely, the first generations in the audio systems and rigid disk drives markets and the fourth generation in the tire cord market.

Table 5 shows that the acceleration parameter $\delta$ is not significant for all product categories except steel making. That is, we observe no acceleration in the diffusion parameters across a wide range of product markets. This result holds also for the case in which we allow the multiplier to be different for $p$ and $q$ with $p_{i}=\left(1+\delta_{p}\right) p_{i-1}$ and $q_{i}=\left(1+\delta_{q}\right) q_{i-1}$. Thus, we assumed a uniform acceleration of $p$ and a different uniform acceleration for $q$.

\section{Conclusions and discussion}

We have shown that the acceleration in the time to takeoff is due to the passing of time and not to generational shifts. Thus, time indeed is a factor that accelerates early growth but generational shifts do not. This result also holds when controlling for the effects of market vintage whether the market is business-to-business or business-toconsumer and whether the technology is a process or product technology. We also show that intergeneration acceleration occurs in the time to takeoff but not in the diffusion parameters, i.e., newer generations of a product enjoy a shorter left tail but a similar overall growth process.

Our results are relevant to marketing executives. Acceleration in the time to takeoff across generations implies that companies that bring next-generation innovations to market need to tool up manufacturing and marketing resources at an ever-increasing pace. However, this suggests that companies can achieve a faster return on their investment as the new generation will show sizeable sales earlier than the previous generation. As Van den Bulte (2000) states, the fact that this acceleration is caused by vintage, i.e., is attributed to broad macroeconomic and demographic changes, should not be a substantial problem for firms as these are factors that firms must already cope with.

Takeoff acceleration does not imply a faster overall diffusion process. Since the general diffusion pace does not change, managers should not be misled by the takeoff acceleration and think that it means a faster growth or earlier peak of sales. Therefore, forecasts as well as investments should be managed accordingly.

Pulling the plug on a new technology is an important decision with tremendous implications (Foster et al. 2004; Garber et al. 2004). Our consistent finding that the time to takeoff shortens over time implies that, if a new technology generation takes longer to take off than the previous generation, it is a signal that the technology may be a commercial failure and may even be in danger of being leapfrogged by consumers. In this situation, management should seriously consider withdrawing support from that technology and placing more resources in the future technology generation to speed up its release and/or acceptance. 


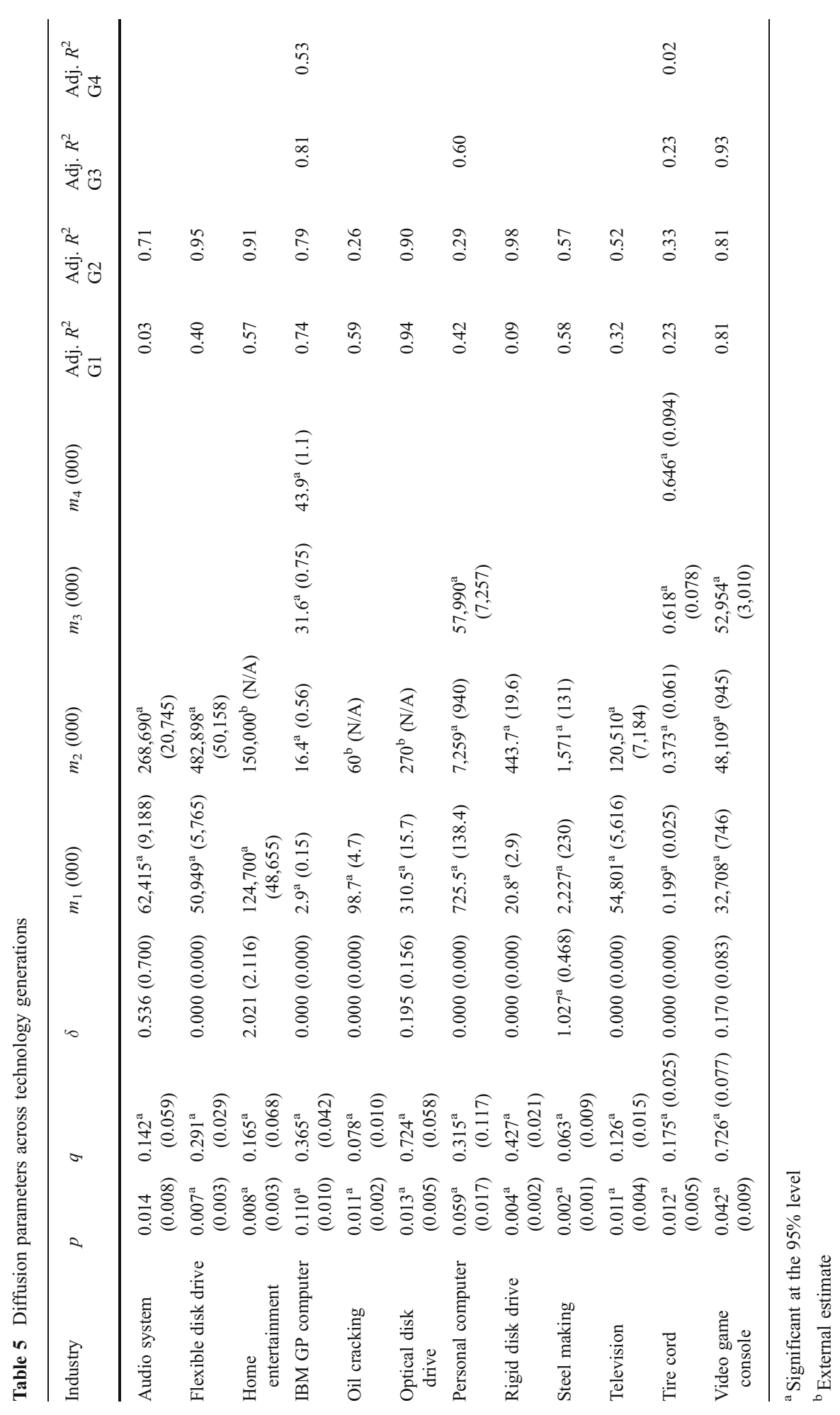


Many, if not most, new product managerial concerns relate to the very early stages of the product life cycle at which point little or no data exist. To predict adoption patterns, managers can use an analogy with an existing product with similar attributes or market characteristics so that the parameters in the mixed influence model (Bass 1969) can be imputed (Ofek 2005). One obvious analogy one can draw is prior technology generations (Bass and Bass 2001 and 2004). Our research shows that such an approach is useful as diffusion parameters often do not change over generations. However, since the time to takeoff does show acceleration across technology generations, using such an analogy to forecast the time to takeoff is not straightforward especially if substantial time has passed between generations.

Acknowledgements The authors would like to thank Barak Libai and Christophe Van den Bulte for their helpful comments and suggestions. The authors also like to thank Portia Bass, Frank Bass, Jae Pae, and Donald Lehmann, who graciously contributed to our sample in providing us with data. The authors acknowledge the research assistance of Lorenz Brongers and Yael Harmatz.

Open Access This article is distributed under the terms of the Creative Commons Attribution Noncommercial License which permits any noncommercial use, distribution, and reproduction in any medium, provided the original author(s) and source are credited.

\section{Appendix: a technological substitution model}

The model we present follows much along the lines of Mahajan and Muller (1996), but we develop a more precise specification of the substitution process; see Fig. 1 (for a more detailed discussion on technological substitution see Peres et al. 2010).

Assume that, at time $t$, there are $k$ technology-generations that operate in the market. Each generation increases the market potential from $m_{i-1}$ to $m_{i}$. We make the following assumptions. After the entry of generation $i$, the older generation $i-1$ continues to acquire customers from $m_{i-1}$. Generation $i$ acquires new adopters from $m_{l}-m_{i-1}$ and upgraders from $m_{i-1}$. The approximation we make here that the newer generation does not acquire new adopters from the market potential of the previous generation is reasonable for our data since the differences in market potential are large. "Upgraders" to generation $i$ are customers of generation $i-1$ who switched to the newer generation $i$ due to marketing efforts and communication with generation $i$. We denote $N u_{i-1, i}(t)$ as the cumulative number of customers who had ever upgraded from generation $i-1$ to generation $i$; note that some customers may have later upgraded further to newer generations as illustrated in Fig. 1. We define $d N u_{i-1, i} / d t=$ $\left(p_{i}+q_{i} N_{i} / m_{i}\right) N_{i-1}$. For the simplicity of the model, we assume no leapfrogging, i.e., no upgrading beyond the subsequent generation. We denote "newcomers" to generation $i$ as adopters of generation $i$ who did not own a previous generation and thus arrive from $m_{i}-m_{i-1}$. The number of newcomers acquired by generation $i$ at time $t$ is given by $d N c_{i} / d t=\left(p_{i}+q_{i} N_{i} / m_{i}\right)\left(m_{i}-m_{i-1}-N_{i}+N u_{i-1, i}-N u_{i, i+1}\right)$.

Note that, when calculating the remaining market potential for newcomers in the second brackets, we subtracted $N_{i}$ from $m_{i}-m_{i-1}$, and we also compensated for those customers who are no longer in $N_{i}$ since they upgraded minus those who upgraded to $N_{i}$ but arrived from $m_{i-1}$. 


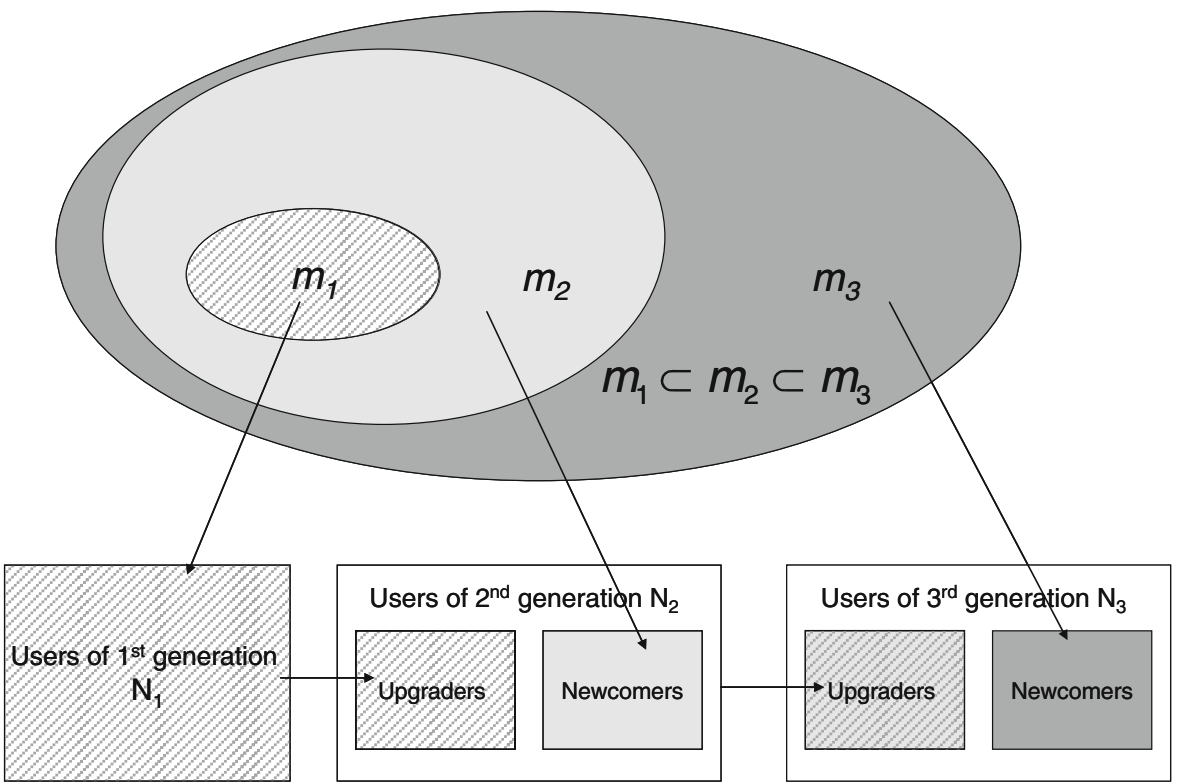

Fig. 1 Technological substitution model in a three-generation market

If $N_{i}(t)$ is the number of customers of generation $i$ at time $t$, then under the above assumptions the growth of each generation can be described as follows.

For the first generation:

$$
d N_{1} / d t=\left(p_{1}+q_{1} N_{1} / m_{1}\right)\left(m_{1}-N_{1}-N u_{12}\right)-\left(p_{2}+q_{2} N_{2} / m_{2}\right) N_{1}
$$

For generations $1<i<k$ :

$$
\begin{aligned}
d N_{i} / d t= & \left(p_{i}+q_{i} N_{i} / m_{i}\right)\left(m_{i}-m_{i-1}-N_{i}+N u_{i-1,1}-N u_{i, i+1}\right) \\
& ++\left(p_{i}+q_{i} N_{i} / m_{i}\right) N_{i-1}-\left(p_{i+1}+q_{i+1} N_{i+1} / m_{i+1}\right) N_{i}
\end{aligned}
$$

For the last generation $(i=k)$ :

$$
\begin{aligned}
d N_{k} / d t= & \left(p_{k}+q_{k} N_{k} / m_{k}\right)\left(m_{k}-m_{k-1}-N_{k}+N u_{k-1,1}\right) \\
& +\left(p_{k}+q_{k} N_{k} / m_{k}\right) N_{k-1}
\end{aligned}
$$

The upgraders:

$$
d N u_{i-1, i} / d t=\left(p_{i}+q_{i} N_{i} / m_{i}\right) N_{i-1}
$$

To understand the logic behind these equations, one should regard the growth of a generation as a result of incoming and outgoing customer streams. Each of the intermediate generations has an incoming stream of newcomers, an inwards stream of upgraders from the previous generation, and an outgoing stream of upgraders to the next generation with only outgoing upgraders for the first generation and only incoming upgraders for the last. 
To assess the reliability of the model, we performed a series of simulations in which we generated data with our model, estimated the parameters, and observed whether our model returned the correct parameters. Simulations were conducted using 300 sets of parameters selected randomly from all the possible combinations. For all the simulations, the model estimated the correct parameters, that is, the difference between the estimated parameters and the original parameters were not significant.

To assess acceleration, one can estimate the above set of equations using the parameters $p_{i}$ and $q_{i}$. Another alternative is to assume a uniform acceleration rate between generations, i.e., an acceleration that is identical for $q$ and $p$, and is denoted by $\delta$ such that $p_{i}=(1+\delta) p_{i-1}$ and $q_{i}=(1+\delta) q_{i-1}$. Using uniform acceleration significantly reduces the number of parameters and enables an explicit, straightforward acceleration analysis. This is especially relevant for products with many generations. We also tried a different multiplier for $p$ and $q$ and thus, we assumed a uniform acceleration of $p$ and a different uniform acceleration for $q$, that is, $p_{i}=\left(1+\delta_{p}\right) p_{i-1}$ and $q_{i}=\left(1+\delta_{q}\right) q_{i-1}$. The results of these new runs are the same; the parameters $\delta_{p}$ and $\delta_{q}$ were found to be nonsignificant for all 12 product markets. However, the number of significant $p$ and $q$ parameters of this latter formulation was considerably less than with the uniform distribution reported in Table 5.

We used the four equations with $p_{i}=(1+\delta) p_{i-1}$ and $q_{i}=(1+\delta) q_{i-1}$ to estimate the model parameters. Note that the terms $N_{\mathrm{u}}$ are unobserved. Data are available only for $N_{1}, N_{2} \ldots N_{k}$, and their derivatives. The number of upgraders $d N_{u i-1, i} / d t$ is calculated based on $N_{i-1}$ and $N_{i}$ using Eq. 4, and $N_{u i-1, i}$ is calculated recursively. Parameter estimations were done on SAS using the seemingly unrelated regression option of the MODEL procedure.

\section{References}

Abell, D. F. (1980). Defining the business: The starting point of strategic planning. Englewood Cliffs: Prentice-Hall.

Agarwal, R., \& Bayus, B. L. (2002). The market evolution and takeoff of product innovations. Management Science, 48(8), 1024-1041.

Bass, F. M. (1969). A new product growth model for consumer durables. Management Science, 15(6), $215-227$.

Bass, P. (2004). Note on data for IBM USA computer generations. Working paper.

Bass, P., \& Bass, F. M. (2001). Diffusion of technology generations: A model of adoption and repeat sales. Working paper.

Bass, P., \& Bass, F. M. (2004). IT waves: Two completed generational diffusion models. Working paper.

Bayus, B. L. (1994). Are product life cycles really getting shorter? Journal of Product Innovation Management, 11, 300-308.

Chandrasekaran, D., \& Tellis, G. J. (2008). Global takeoff of new products: Culture, wealth, or vanishing differences? Marketing Science, 27(5), 844-860.

Christensen, C. M. (1993). The rigid disk drive industry: A history of commercial and technological turbulence. The Business History Review, 67(4), 531-588.

Cox, D. R. (1972). Regression models and life tables. Journal of the Royal Statistical Society, Series B, 34, $187-220$.

Cox, D. R. (1975). Partial likelihood. Biometrika, 62(2), 269-276.

Danaher, P. J., Hardie, B., \& Putsis, W. (2001). Marketing-mix variables and the diffusion of successive generations of technological innovation. International Journal of Marketing Research, 38(4), 501-514.

Foster, J. A., Golder, P. N., \& Tellis, G. J. (2004). Predicting sales takeoff for Whirlpool's new personal valet. Marketing Science, 23(2), 182-185. 
Garber, T., Goldenberg, J., Libai, B., \& Muller, E. (2004). From density to destiny: Using spatial dimension of sales data for early prediction of new product success. Marketing Science, 23(3), 419-428.

Goldenberg, J., Libai, B., \& Muller, E. (2010). The chilling effects of network externalities. International Journal of Research in Marketing, 27(1).

Golder, P. N. (2000). Historical method in marketing research with new evidence on long-term market share stability. Journal of Marketing Research, 37(2), 156-172.

Golder, P. N., \& Tellis, G. J. (1997). Will it ever fly? Modeling the takeoff of really new consumer durables. Marketing Science, 16(3), 256-270.

Golder, P. N., \& Tellis, G. J. (2004). Growing, growing, gone: Cascades, diffusion, and turning points in the product life cycle. Marketing Science, 23(2), 207-218.

Han, A., \& Hausman, J. A. (1990). Flexible parametric estimation of duration and competing risk models. Journal of Applied Econometrics, 5(1), 1-28.

Islam, T., \& Meade, N. (1997). The diffusion of successive generations of a technology: A more general model. Technological Forecasting and Social Change, 56(1), 49-60.

Kim, N., Chang, D. R., \& Shocker, A. (2000). Modeling intercategory and generational dynamics for a growing information technology industry. Management Science, 46, 496-512.

Kohli, R., Lehmann, D. R., \& Pae, J. (1999). Extent and impact of incubation time in new product diffusion. Journal of Product Innovation Management, 16(2), 134-144.

Kovac, F. (1969). Tire reinforcing systems (2nd ed.). The University of Akron Lecture Series, the Goodyear Tire \& Rubber Company.

Kuester, S., Montaguti, E., \& Robertson, T. S. (1998). How new technologies can take off fast. Financial Times, October 19.

Mahajan, V., \& Muller, E. (1996). Timing, diffusion, and substitution of successive generations of technological innovations: The IBM mainframe case. Technological Forecasting and Social Change, 51(2), 109-132.

Norton, J. A., \& Bass, F. M. (1987). A diffusion theory model of adoption and substitution for successive generations of high-technology products. Management Science, 33(9), 1069-1086.

Norton, J. A., \& Bass, F. M. (1992). The evolution of technological generations: The law of capture. Sloan Management Review, 33, 66-77.

Ofek, E. (2005). Forecasting the adoption of a new product. Harvard Business School case HBS 505-062. Cambridge, MA: Harvard Business School.

Pae, J. H., \& Lehmann, D. R. (2003). Multigeneration innovation diffusion: The impact of intergeneration time. Journal of the Academy of Marketing Science, 31(1), 36-45.

Parker, P. M. (1992). Price elasticity dynamics over the adoption life cycle. Journal of Marketing Research, 29(3), 358-367.

Peres, R., Muller E., \& Mahajan V. (2010). Innovation diffusion and new product growth models: A critical review and research directions. International Journal of Research in Marketing (forthcoming).

Phister, M., Jr. (1979). Data processing technology and economics (2nd ed.). Bedford: Santa Monica Publishing Company and Digital Press.

Sood, A., \& Tellis, G. J. (2005). Technological evolution and radical innovation. Journal of Marketing, 69 (3), 152-163.

Stremersch, S., Tellis, G. J., Franses, P. H., \& Binken, J. L. G. (2007). Indirect network effects in new product growth. Journal of Marketing, 71, 52-74.

Tellis, G. J., Stremersch, S., \& Yin, E. (2003). The international takeoff of new products: Economics, culture, and country innovativeness. Marketing Science, 22(2), 188-208.

Van den Bulte, C. (2000). New product diffusion acceleration: Measurement and analysis. Marketing Science, 19(4), 366-380.

Van den Bulte, C. (2002). Want to know how diffusion speed varies across countries and products? Try using a Bass model. PDMA Visions, 26, 12-15.

Van den Bulte, C. (2004). Multigeneration innovation diffusion and intergeneration time: A cautionary note. Journal of the Academy of Marketing Science, 32, 357-360.

Van den Bulte, C., \& Stremersch, S. (2004). Social contagion and income heterogeneity in new product diffusion: a meta-analytic test. Marketing Science, 23, 530-544.

Van den Bulte, C., \& Stremersch, S. (2008). Contrasting early and late new product diffusion: Speed across time, products and countries. Working paper.

Van Everdingen, Y., Fok, D., \& Stremersch, S. (2009). Modeling global spill-over of new product takeoff. Journal of Marketing Research, 46(5), 637-652. 